\title{
The biotech speculator
}

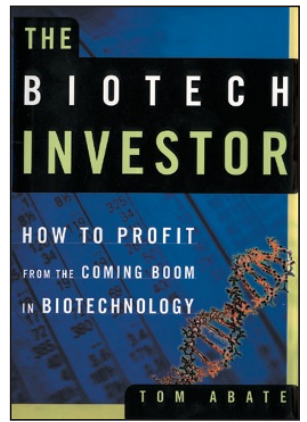

\section{The Biotech Investor: How to Profit from the Coming Boom in Biotechnology \\ by Tom Abate}

Times Books, $\$ 26$

289 pp. hardcover

ISBN 0-8050-7069-9, 2003

Reviewed by Robert Teitelman

Biotechnology has always been a formidable challenge to investors. Ever since the first IPOs in the early 1980s, biotechs have wrestled with a complex, evolving science that was clearly not ready to generate much in the way of commercial products. The enterprise required long lead times, a tortuous regulatory path and ever-greater infusions of capital.

For investors, biotech was like trying to read Shakespeare through multiple fish tanks. If bench scientists weren't sure that a particular variation of interleukin or interferon would have a salutary effect on a cellular mechanism, the entrepreneur or venture capitalist had even less of an idea, and they were followed, in descending order, by analysts, institutional and retail investors, and the media. Finally, biotechs nearly always ran losses, defeating efforts by investors to establish rational valuations.

Two decades later, little has changed, save that a handful of biotechs now make money. Also, as Tom Abate, a columnist for the San Francisco Chronicle describes in The Biotech Investor: How to Profit from the Coming Boom in Biotechnology, there are now hundreds of biotechs pursuing everything from genomics to proteomics to bioinformatics.

Abate has the dual goals of describing the industry and providing the tools for investors to deal with the field. In pursuit of his first goal, Abate does a commendable job, defining terms, broadly describing the basic science, outlining how drugs are approved and-a bit sketchily perhaps-how the financial underpinnings operate. He is a patient guide, sensitive about taking readers into realms beyond their expertise, but also quick to warn them of perils on the way.

Molecular biologists and Wall Street analysts are not Abate's target audience. He assumes that his typical reader took biology in high school, has no idea how the Food and Drug Administration works and has never really pondered corporate balance sheets. That's where his problems begin, particularly when he tries to offer investing advice. In effect, Abate's first goal wars with his second. Biotech investing, with its whipsawing alternations of euphoria and depression, has proven to be treacherous to the most experienced of investors, who not only have historical and technical knowledge, but who can command the kind of access to information that consumers, scanning newspapers, Googling the web or ordering up annual reports (all of which he suggests) will never possess.

Abate tries hard to justify his subtitle: that a 'boom' is coming, which

The author is at the financial weekly The Deal. (http://www.thedeal.com/) ordinary folks can profit from. His argument for that boom is a little loose-he can't really tell you where or when — and he works the negative side first. Biotech is not going to blow up like the dot-coms, he declares; it's been around, after all, for 50 years. (In fact, Watson \& Crick's breakthrough may be 50, but the industry itself is less than half that. That conflation of science and technology is all-too typical.) Combine all that science and all those companies (supply) with an aging population (demand) and you get a boom.

The trouble is, Abate himself doesn't really believe it's as simple as that. For much of the book, he tries to apply the kind of disciplines that may work (but often don't) with companies that have more predictable earnings streams. He wants his reader, like a kind of biotech Warren Buffett, to carefully consider risk and place his money on companies that have a high probability of panning out. Don't throw money at microcaps, he warns; check to see that a company has a product in phase III; make sure it hasn't burned through its cash; investigate licensing deals with big pharma; check that it's working in a sector with promise and that its intellectual property is buttoned-up tight.

But there are difficulties. First, Buffett himself has long regarded investing in technology generally as a loser's game. And for all the risks, software, hardware and chip enterprises are far more predictable over a shorter cycle than biotech, if only because they're driven more by technology than by basic science.

Second, Abate eventually confirms that biotech is less about 'investment,' buying and holding in the Buffett sense, and more about speculation, that is, trading in and out of stocks based on a perception of where shares are going. Two-thirds of the way through his book, Abate visits a professional money manager, Kurt von Emster, who argues that individuals will get killed just sitting on biotech stocks. "Most investors think the only way to make money is to go long and hold, and that's just not so," he says. Von Emster insists-and Abate agrees-that investors can learn to outthink the market simply by doing a little homework and filling out a checklist he kindly provides. In other words, biotech investors need not only to master the industry itself but also to learn the ways of the market.

That's insane advice-particularly from this decent primer-and it rips away the facade of reasonableness Abate tries hard to maintain. Boom or no boom, amateurs who try to master both the industry and the market will be swallowed whole. In fact, large numbers of amateurs believing they could outthink and outtrade the market fueled the tech bubble. For years, academic studies have repeatedly emphasized the difficulties even professionals have in beating the market. Wall Street and professional investors are just waiting out there to trade against amateurs playing their game, particularly in this most speculative, and most information-sensitive, of industries.

Will the boom that lifts all biotech ships come some day? Probably, and perhaps soon. The science will inevitably mature and ripen into more predictable commercial technology. But even then, the question lingers: will the fruits of that science, from an investing standpoint, be harvested by the vast number of startups, or migrate upstream to big pharma? That's a question investors should wrestle with before they fill out their checklists and kick-start their day trading. The longer they take to answer, the better off they'll be. 